\title{
Subjective Evaluation of Classroom Acoustics by Teenagers vs. Reverberation Time
}

\author{
P. LEŚNA* AND E. SKRODZKA \\ Institute of Acoustics, Adam Mickiewicz University, Umultowska 85, 61-114 Poznań, Poland
}

\begin{abstract}
A questionnaire was developed to evaluate acoustics in classrooms. The group of 279 pupils from 7 schools in age from 11 till 17 years were tested. The subjective evaluation was accompanied by objective measurements of reverberation time in 11 classrooms. The questionnaire was based on five point differential scales and consisted of six questions about acoustic comfort, teacher voice clarity, speech comprehension, evaluation of different noise sources intensity, annoyance and consequences of noise in the classroom. The results of statistical analysis of subjective answers and physical measurements of reverberation time were correlated. After analysis it was found that clarity of teacher voice and speech comprehension scores lowered for increasing reverberation time and was not statistically significant. Acoustic comfort score was also lower for increasing reverberation time but only in a group of pupils older than 12 years. For children under 12 years the results of questionnaire's analysis were not so clear as for older pupils.
\end{abstract}

PACS numbers: $43.55 \mathrm{Hy}$

\section{Introduction}

The purpose of our research was the classification of classrooms in Polish schools based on subjective and objective measurements. The paper is a part of a comprehensive study and presents subjective evaluation by teenagers of classroom acoustics vs. reverberation time. Noise inside classrooms has been an increasing problem in almost all school buildings. The acoustical condition in classrooms appear to have attracted worldwide attention especially in primary schools and integrated schools. Quality of the acoustical environment is a significant element of the verbal learning [1]. In 1991 in Poland appeared low regulations about integration of healthy children and those who have some health deficits like e.g. ADHD, ADP, hearing impairment, visual impairment [2]. Those children, more than others, need a good acoustical quality of classrooms for learning. Thus, there is a strong need to provide data to classify and define a quality of classrooms in Poland. There were lots of objective research about acoustics in Polish schools [3-7], evaluation of the acoustical climate in classrooms [8-9] and subjective measurements using questionnaires $[3,10]$. However, there is less results about subjective measurements with pupils in age 11 till 17 . Our research was partly based on methodology and results concerning teacher's, children's and student's perception of noise in classrooms, acoustic comfort and evaluation of different noise sources intensity [11-16] as well as reports about questionnaires with five to six point differential scales or category scales [12-14].

* corresponding author; e-mail: paula@spl.ia.amu.edu.pl

\section{Methodology}

\subsection{Questionnaire development and administration}

The questionnaire was developed to 279 pupils from seven schools. The subjects were in age from 11 till 17 years. There were 100 boys and 179 girls. A literature review, interview with teenagers and preliminary questionnaire version were done. Pilot study in three classrooms from one school before completed contraction was performed. The final questionnaire 1 contained six questions. It was based on point differential scales (five questions) and category scale (one question). This subjective survey ascertained children's perception of acoustic comfort, teacher's voice clarity, speech comprehension, annoyance, evaluation of different noise sources intensity, consequences of noise in classroom (similarly to $[13,15]$ ). Questionnaire administration took place of one month period in 11 classrooms chosen from six schools in Poznań and one in Czarnków. Pupils filled out questionnaires during the first six minutes of class time. Data were immediately collected by the researcher. There were groups of 14-30 children in each classroom.

\subsection{Data analysis}

A total 279 questionnaires were analyzed. There were some missing values in the youngest group of subjects. Data of question about acoustic comfort were not so clear in the group of children under 12 years because children in this age did not understand what acoustic comfort was. It caused that the next small questionnaire (questionnaire 2) with different acoustic comfort's question was contracted. The youngest and the oldest groups of 94 subjects from 2 schools were tested in that research. 


\subsection{Physical measurements}

To obtain the values of physical quantities characterizing classrooms' acoustics, acoustical measurements in three classrooms were done. Four to six microphone locations points (depending on the size of the room) distributed throughout pupil's seating area in each classroom were considered. Reverberation time measurements were made by using maximum length sequence system analyser (MLSSA) system with signal source located at the typical teaching position. Data of reverberation time values in nine remaining classrooms were taken from [7]. All collected data of reverberation time were correlated to subjective answers known from questionnaires.

\section{Results}

\subsection{Characteristics of teenagers}

The subjects ranged from fifth form of primary school (11 years old) to last form of secondary school (17 years old). The mean age was 14, 5 years; 100 boys and 179 girls took part in investigation. There were 129 pupils from three secondary schools and 150 from four primary schools. In the group of teenagers in age between 15-17 years there were $71 \%$ of girls and $29 \%$ of boys. In the group of children younger than 15 years there were $46 \%$ of girls and $54 \%$ of boys.

\subsection{Characteristics of the classrooms}

Investigated classrooms varied from small lecture rooms with volume $137 \mathrm{~m}^{3}$ and about 20 seating places to rooms with volume $306 \mathrm{~m}^{3}$ and over 35 seating places. A reverberation time ranged from $0.7 \mathrm{~s}$ to $2.81 \mathrm{~s}$. There were 3 rooms with reverberation time equal $1 \mathrm{~s}$ and only one had less than $1 \mathrm{~s}$. Remaining 7 classrooms had reverberation time from $1.3 \mathrm{~s}$ till $1.9 \mathrm{~s}$. Answers from questionnaire 1 in room no. 12 with reverberation time equal $2.81 \mathrm{~s}$ were excluded from analysis. Subjects in that classroom where under 12 years old and have problems with understanding questions. However, the questionnaire 2 was performed in this room. In that classroom the youngest pupils (under 12 years) were studying.

\subsection{Subjective evaluation of classroom acoustics} 3.3.1. Results of questionnaire 1

In Figs. 1-2 the average pupils' responses to four questions vs. reverberation time are shown. The maximum possible rating was 5 and the minimum rating was 1 . Figs. 1-2 show that the whole scale was used by subjects. It was found that clarity of teacher's voice and speech comprehension scores lowered for increasing reverberation time, but there was no significant correlation between scores (Figs. 1a and 2a).

Pupils' responses for question about acoustic comfort also lowered for increasing reverberation time but only in a group of pupils older than 12 years. In Fig. $2 \mathrm{~b}$ there are scores of 11 classrooms (without room no. 12 where the
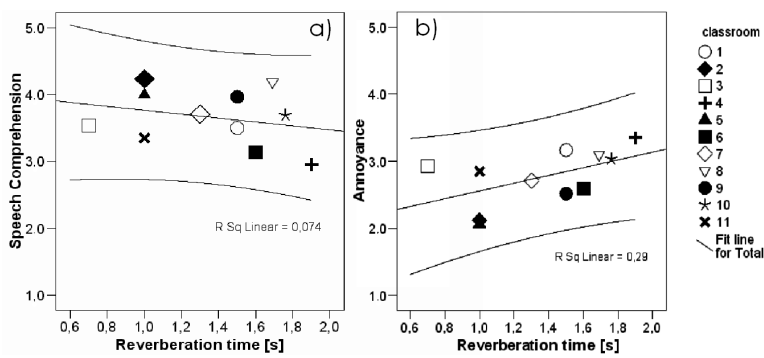

Fig. 1. Speech comprehension and annoyance vs. reverberation time.

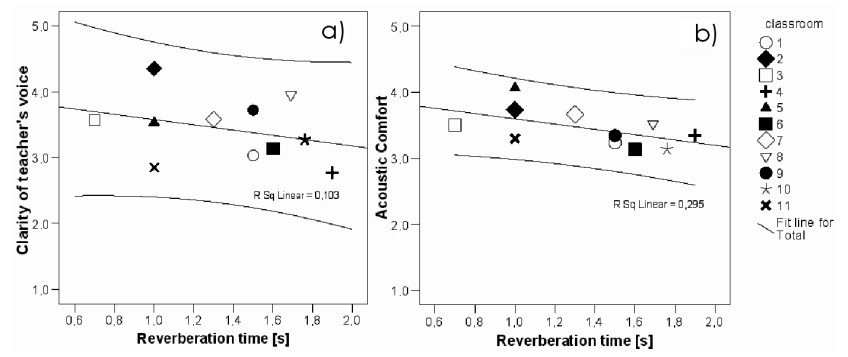

Fig. 2. Clarity of teacher's voice and acoustic comfort vs. reverberation time.

youngest children were tested, which was excluded). In the contrast, annoyance scores (Fig. 1b) increased monotonically with increasing reverberation time. Teenagers evaluated noise in the classroom and noise in corridor as the most intensive noise sources. The average responses were 3.2 and 3.4 respectively. Noise from other classrooms as well as noise inside and outside the building were not significant noise sources for pupils. Only $2.8 \%$ of subjects had seen none consequences of noise in classroom. About $73 \%$ of pupils reported decreasing of teacher's voice as the most important consequences of noise. More than half of all tested pupils thought that noise caused decreasing of attention (68\%), headache $(28 \%)$ and decreasing of a perception of students' questions (24\%).

\subsubsection{Results of questionnaire 2}

The youngest and the oldest children's scores of their evaluation of classrooms vs. reverberation time are shown in Fig. 3.

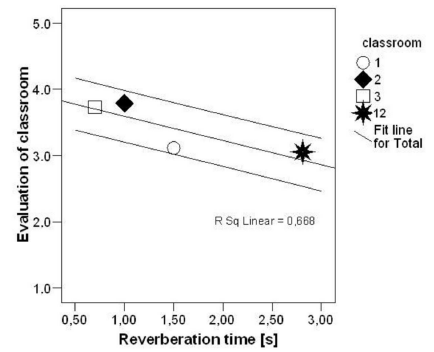

Fig. 3. Evaluation of classroom vs. reverberation time. 
For the classroom no. 12, where results of the questionnaire 1 were not so clear, questionnaire 2 was tested. There was strong correlation between scores $(R=0.668)$ and relationship between reverberation time and pupils' evaluation of rooms was observed.

\section{Discussion and conclusion}

The current study aimed to ascertain children's perception of acoustic comfort, teacher's voice clarity, speech comprehension, annoyance, evaluation of different noise sources intensity and consequences of noise in classroom. The purpose was also to checked how students' responses correlate with objective measurements of classroom's reverberation time. Evaluation was influenced by the age of pupils. Collected data demonstrate that children under 12 years did not know what the acoustic comfort was. Generally acoustic comfort score was lower for higher reverberation time except a group of pupils under 12 years. Improved question's construction changed the scores, as was observed for questionnaire 2 - there was high correlation between general children's evaluation of classroom and reverberation time. The ratings for annoyance monotonically increased with reverberation time increasing. The ratings for acoustics comfort monotonically decreased with increasing reverberation time. As the most intensive noise sources pupils evaluated noise in classrooms and noise in corridors. The majority of tested group had felt the consequences of noise in classroom $(97.2 \%)$. More then half of them reported of decreasing of teacher's voice (73\%) and decreasing attention (68\%) as the most important consequences of noise.

\section{References}

[1] Z. Karabiber, M. Vallet, Classroom acoustics policies - An overview, Proc. Euronoise 2003, 048-OL/p. 1 - 048-OL/p. 6 (2003).

[2] The Journal of Laws No 256 item 2572, Poland 2004, (in Polish).

[3] P. Pękala, P. Leśna, Archives of Acoustics 30, 4, 209 (2005).

[4] J. Smirnowa, P. Pękala, Classroom Acoustics in Poland - Preliminary Research, Proc. OSA (2002).

[5] Z. Koszarny, A. Chyla, PZH 54, 311 (2003).

[6] Z. Koszarny, D. Jankowska, PZH XLVI, 3 (1996).

[7] K. Pańczak, Acoustical Evaluation of Selected Schools in Poznań by Teachers and Pupils, M. Sc Thesis, A. Mickiewicz University in Poznań, Poznań (2006).

[8] M. Błaszak, Factors determining acoustic comfort in school buildings, M. Sc Thesis, A. Mickiewicz University in Poznań, Poznań 2005.

[9] A. Ossowski, J. Smirnowa, Evaluation of the acoustical climate in classroom with respect to the speech intelligibility, Proc. OSA 2004, 241 (2004).

[10] Z. Koszarny, PZH XLIII, (2) (1992).

[11] J.E. Dockrell, B. Schield, J. Acoust. Soc. Am. 115, 2964 (2004)

[12] S.M. Kenedy, M. Hodgson, L.D. Edgett, N. Lamb, R. Rempel, J. Acoust. Soc. Am. 119, 299 (2006).

[13] A. Astolfi, V. Corrado, M. Filippi, S. Viazzo, Classroom acoustic assessment: Analysis of subjective analysis and measured indices, Proc. Euronoise 2003, 392-IP/p. 1 (2003).

[14] M. Losso, E. Viveiros, T. Figueiredo, Subjective evaluation of acoustical conditions in educational buildings in Brazil, ICA 2004, II-925 - II-928 (2004).

[15] P.H.T. Zannin, C.R. Marcon, Appl. Ergon. 38, 675 (2007).

[16] J. Valentine, O. Wilson, G. Dodd, K. McGunnigle, A. Hellier, J. Wood, New Zealand Acoustics, Vol. 14, No 2 (2001) 